\title{
UNLOCKING THE TIME-CAPSULE OF HISTORIC AERIAL PHOTOGRAPHY TO MEASURE CHANGES IN ANTARCTIC PENINSULA GLACIERS
}

\author{
By ADRIAN FOX (AJFO@BAS.AC.UK) and ANDREAS CZIFERSZKY \\ (ANCZ@BAS.AC.UK) \\ British Antarctic Survey, Cambridge, UK
}

\begin{abstract}
Recent studies have reported widespread retreat and acceleration of glaciers on the Antarctic Peninsula, attributed to regional warming. The loss of ice is a contributor to sea-level rise, but its volume and impact on sea level is poorly known. There are few ground measurements of ice thickness change and existing satellite altimeters are ineffective over the mountainous terrain.

An accurate assessment of changes in surface height, and hence ice volume, of glaciers on the Antarctic Peninsula over past decades is needed to aid better estimates of their past impact on sea-level rise and predictions of their future contribution.

There is an archive of over 30,000 aerial photographs going back to the 1940s for parts of the Antarctic Peninsula and photogrammetry of time-series of these historic photographs is now the only way to reconstruct changes in glacier surface height over the last fifty years. However, the historic aerial photographs are difficult to use for detailed measurements due to inadequate ground control, unfavourable sortie characteristics, incomplete calibration data and use of paper prints.

This paper describes a method to provide control for historic photos without ground fieldwork by linking them to a newly-acquired, highly-accurate photogrammetric model adjusted through direct kinematic GPS positioning of the camera. It assesses the achievable accuracy through a worked example using a glacier on the Antarctic Peninsula with typical aerial photography at five dates from 1947 to 2005.

Overall measurement accuracy of better than $2 \mathrm{~m}$ RMSE in $X, Y$ and $Z$ was achieved for all the photography types, which is precise enough to allow reliable measurement of changes in ice thickness for the glacier over decadal periods. The principal constraints are image quality of the historic photographs and using paper prints.
\end{abstract}


KEYWORDS: Antarctic Peninsula, block adjustment, calibration, Digital Elevation Model, historic aerial photography, ice volume change

\section{INTRODUCTION}

The Antarctic Peninsula north of $70^{\circ} \mathrm{S}$ covers less than $0 \cdot 8 \%$ of the area of the entire grounded ice sheet in Antarctica, but receives about $8 \%$ of its snowfall (van Lipzig, et al., 2004). The amount of ice in the region is not accurately known, but a conservative estimate is that it contains enough ice to raise global sea level by $5-10 \mathrm{~cm}$. Recent investigations have demonstrated clear evidence that the ice sheet of the Antarctic Peninsula is being affected by contemporary climatic change, with warming of mean annual temperatures of more than $2.5^{\circ} \mathrm{C}$ since the 1950 s - a rate unprecedented over the last two millennia and amongst the strongest in the southern hemisphere (King, 2003; Vaughan, et al., 2003). In addition, the number of days per year on which melting of ice can occur has increased by up to 74\% since 1950 (Vaughan, 2006).

Research using existing aerial photographs and satellite images has shown many cryospheric responses to the climate changes: Ice shelves on both the east and west coasts have suffered progressive retreat and then abrupt collapse (Morris and Vaughan, 2003; Scambos, et al., 2000); the glaciers that supply those ice shelves with ice have accelerated (Rignot, et al., 2004; Rignot, et al., 2005; Rott, et al., 1996; Scambos, et al., 2004); 87\% of glaciers that reach the sea (rather than an ice-shelf) have retreated over the last 40 years (Cook, et al., 2005) and the flow rate of these glaciers has increased by about 12\% over the last 12 years (Pritchard and Vaughan, Submitted). Taken together, these studies suggest that the Antarctic Peninsula is currently contributing to global sea-level rise at a rate of $0 \cdot 16 \pm 0.06$ $\mathrm{mm} \mathrm{a}^{-1}$, which is probably similar to other fast-changing, sub-polar glacier systems such as Alaska.

The existing studies, however, only describe the broad connection between climate change and the response of the cryosphere, the underlying changes in ice volume are unknown. There are two main reasons for the current lack of data on the Peninsula glaciers. Firstly, the size and remoteness of the region, steep topography, and difficult surface conditions mean that most Antarctic Peninsula glaciers are inaccessible to field-workers and only a few in situ records of change exist (Morris and Mulvaney, 2004; Smith, et al., 1998). Secondly, while more than a decade of continuous satellite altimetry has allowed mapping of elevation change for most of continental Antarctica, the changes in the volume of the Antarctic Peninsula ice-sheet remain unquantified because the ice slopes are too steep for existing sensors. Whilst a new generation of satellite altimeters (e.g. Cryosat-2 due for launch 2009/2010) and time-variable gravity measurements from space (GRACE) may begin to measure change occurring over the next decade, they cannot look back in time and warming has been underway for at least 50 years. Thus there is an urgent need for an accurate assessment of changes in 
surface height, and hence volume, of glaciers on the Antarctic Peninsula over past decades, to aid better estimates of their past impact on sea-level rise and predictions of their future contribution.

Similar difficulties apply to attempts to quantify changes in ice cover for other sub-polar and high-mountain regions known to be experiencing significant ice loss such as Alaska, Southern Greenland, the Himalayas and Svalbard.

There is an archive of over 30,000 aerial photographs going back to the 1940s for parts of the Antarctic Peninsula, held by the British Antarctic Survey (BAS), US Geological Survey and Royal Air Force. Similar collections exist for some other polar and high-mountain areas. The photographs are 'time-capsules' of information about the glaciers in the region at the time they were taken. Photogrammetry of time-series of these historic photographs is now the only way to reconstruct changes in glacier surface height and hence volume over the last fifty years.

There are well-established methods for measuring glacier volume change using time-series photogrammetry, starting with graphical methods developed by Finsterwalder (1954), through to comparison of Digital Elevation Models (DEMs) of glacier surfaces using digital photogrammetry and GIS systems (eg. Etzelmüller et al., 1997; Rentsch, et al., 1990). Other parts of the world have long-running glacier monitoring programmes and there are many published studies using photogrammetric methods for measuring glacier volume change (eg. Andreassen et al., 2002; Favey et al., 2000).

However, for the Antarctic Peninsula, the historic aerial photographs have always been difficult to use for detailed measurements: (1) The remote rugged terrain has restricted field surveys so that ground control is sparse and inadequate for photogrammetry in almost all areas; (2) The photographs were mainly flown for regional reconnaissance and often have inconvenient sortie characteristics for detailed study or individual glaciers; (3) Some of the photographs have lost their calibration metadata in several changes of ownership over the fifty year period, and (4) The original negatives may be lost or are now damaged or degraded, so that decades-old paper prints may have to be used. This risks introducing bias to the photogrammetric measurements through the effects of paper distortion.

Thus, historic aerial photographs are an underused resource for measuring glacier volume change on the Antarctic Peninsula. Overcoming the problems hindering accurate photogrammetry could unlock a vast archive of glacier change measurements spanning 60 years.

This paper describes a method to provide control for historic photos by linking them to a newly-acquired, highly-accurate photogrammetric model. The approach of using recent photography to transfer control for adjustment of older epochs in difficult mountain environments has had limited use before, for example von Barsch and Hell, (1975) in the Swiss Alps. Here we apply the method with direct kinematic GPS positioning of the camera, to eliminate the need for surveyed ground control in the remote and inaccessible Antarctic Peninsula. This paper presents a worked example for a glacier that has 5 epochs of aerial photography coverage between 1947 and 2005 and an assessment of the achievable measurement accuracy. 


\section{SELECTION AND LOCATION OF THE TEST GLACIER}

Moider glacier, on Pourquoi Pas Island, Antarctic Peninsula (Fig. 1) was selected as the test glacier for this study. It is about $50 \mathrm{~km}$ from the main BAS logistics hub at Rothera Research Station. The rugged terrain is typical of the northern Antarctic Peninsula (Fig. 2) and presents a valid test for wider application of the method in the region. The glacier flows westwards for $10 \mathrm{~km}$ from an upper bowl at about $800 \mathrm{~m}$ altitude, to reach the sea with a triangular tongue of floating ice at Dalgliesh Bay. The upper bowl is mainly smooth featureless snow, but parts of the lower part of the glacier are heavily crevassed, have areas of avalanche debris and sastrugi (wind-sculpted surface features). The glacier develops a substantial glacial lake in most years and has substantial moraines at its edges. The glacier is flanked by mountains rising steeply to icecovered summits at more than $1500 \mathrm{~m}$, with soaring rock walls and narrow, corniced ridges interspersed with ice-falls.

The area is clearly difficult to access for field surveying, and prior to this study contained no ground-surveyed points. This site would present severe difficulties for photogrammetry relying on orientation of the aerial photography to surveyed ground control.

Four historic photography sets, spanning 1947 to 1991, are available, and these include the camera/lens types comprising the majority of the archival aerial photography for the Antarctic Peninsula. New aerial photography was acquired in 2005 specially for this study, using direct GPS measurement of the camera positions.

\section{DATA}

\section{Aerial photography}

The cameras and lenses used for the aerial photography of Moider Glacier, and the availability of calibration metadata and original negatives are summarised in Table I.

The Ronne Antarctic Research Expedition aerial photography from 1947 has no calibration metadata and is only available as paper-prints, similarly the negatives are unavailable for the BAS 1991 photography and paper prints were used.

The image quality of the FIDASE photography is fairly poor; the images are not completely sharp and the negatives are rather scratched. This is attributed to the processing of the negatives in less than ideal laboratory conditions on location in Antarctica and some deterioration over the intervening 50 years. The area coverage of the different sorties is shown in Fig. 3.

New photography for this project was acquired by BAS in January 2005 using a Zeiss RMK camera modified to support direct kinematic GPS measurement of the camera centres. The processing results for the kinematic GPS, over a $50 \mathrm{~km}$ baseline from the GPS base-station at Rothera, showed an RMS accuracy of $0.02 \mathrm{~m}$. Before and after track crossings, on the runway apron, were 
within $0.05 \mathrm{~m}$ in elevation. The aircraft travelled at $60 \mathrm{~m} / \mathrm{sec}$ ( 120 knots / 220 $\mathrm{kph}$ ) during the sortie. The GPS sample interval was $1 \mathrm{~Hz}$ and the actual camera positions were interpolated within the 1-second sample intervals. Whilst a Twin Otter aircraft is a fairly stable platform over 1 second at $4,500 \mathrm{~m}$ altitude, the interpolated camera positions will be less accurate than the directly measured GPS data points. Examination of randomly chosen strings of successive 1-second interval GPS position fixes from the sortie showed that the aircraft trajectory was stable and not prone to short-period variability. The RMS values of the altitude differences between successive fixes were between 0.4 and $0.6 \mathrm{~m}$ over a period of one minute. Thus, interpolation of the camera centres between the 1-second samples is likely to be accurate to a few $\mathrm{cm}$ and not a major source of error for this project.

Only the BAS 2005, IfAG 1989 and FIDASE 1957 aerial photography cover the whole glacier. Fig. 3 shows that the glacier lies on an approximately East to West axis, but the historic aerial photography was either flown on a North to South axis (FIDASE, IfAG) or diagonal to the glaciers (RARE, BAS 1991). The RARE and BAS 1991 aerial photographs were flown at 3000 metres altitude, but the terrain in the area is over 1000 metres in places, so there are areas of 'deadground' that cannot be seen in stereo, and areas with extreme relief-distortion in the mountainous parts of the photographs.

All the photographs are panchromatic, except the BAS 2005 photographs, which used colour negative film and they were all scanned at 20 microns resolution using a photogrammetric-standard scanner.

TABLE I. Characteristics of aerial photography available for Moider Glacier

\begin{tabular}{|c|c|c|c|c|}
\hline $\begin{array}{c}\text { Photography } \\
\text { type }\end{array}$ & Photoscale & Camera model & Lens type & Comments \\
\hline $\begin{array}{l}\text { RARE Nov } \\
1947\end{array}$ & $1: 20,000$ & Fairchild K17 & Metrogon & $\begin{array}{c}\text { Focal length only, paper } \\
\text { prints }\end{array}$ \\
\hline $\begin{array}{c}\text { FIDASE Jan } \\
1957\end{array}$ & $1: 27,000$ & Williamson Eagle IX & Ross 6" & Full calibration \\
\hline $\begin{array}{c}\text { IfAG Feb } \\
1989\end{array}$ & $1: 70,000$ & Zeiss RMK & Pleogon & Full calibration \\
\hline $\begin{array}{c}\text { BAS Jan } \\
1991\end{array}$ & $1: 20,000$ & Zeiss RMK & Pleogon & $\begin{array}{c}\text { Full calibration, paper } \\
\text { prints }\end{array}$ \\
\hline $\begin{array}{l}\text { BAS Feb } \\
2005\end{array}$ & $1: 30,000$ & Zeiss RMK & Pleogon & $\begin{array}{c}\text { Full calibration, GPS } \\
\text { camera centres }\end{array}$ \\
\hline
\end{tabular}

\section{GPS ground survey data}

Whilst it is well-established that GPS-supported aerial photography can be used for photogrammetry without any reference to surveyed ground-control, it is 
good practice to have some surveyed ground-control in the project to check for gross or systematic errors in the airborne kinematic GPS data.

The rugged terrain severely limits suitable places for ground-surveyed control points, but we acquired 5 GPS surveyed ground control points for this project with helicopter support from HMS Endurance for access.

Due to the limited opportunity for access to the test site it was not possible to place ground targets prior to the aerial photography. The ground control points were chosen on conspicuous ground features that were expected to be clearly visible on the BAS 2005 aerial photography. The processing statistics for the five points show that the Ground Control Points are accurate to better than $10 \mathrm{~cm}$ in X, $\mathrm{Y}$ and $\mathrm{Z}$. This is much better than the measurement precision from the photography, which is limited by the ground resolution of the photographs, $(0.6 \mathrm{~m}$ for the BAS 2005 photography).

\section{METHOD}

The overall method is to:

1. Build a high-accuracy photogrammetric block of the new (BAS 2005), GPS supported aerial photography through a bundle adjustment.

2. Transfer secondary control points from the 2005 block to the historic photographs to achieve a photogrammetric orientation for all the photographs.

3. Define the glacier surface at each epoch as a DEM derived from photogrammetric height measurement samples (post points).

4. Difference the DEMs from different epochs to detect change in glacier thickness and hence volume over time.

\section{Orientation of the BAS 2005 aerial photography}

The 2005 GPS-supported aerial photography block comprised 53 photographs flown as three strips with cross strips at each end. It will now be known as the primary block. It was block-adjusted, using Leica Photogrammetry suite (LPS) software, to the directly-measured camera centres and a total of 254 tie-points. The effectiveness of external orientation with GPS-measured camera centres is long established in the literature, for example Lucas (1987); Gruen, et al. (1993); Ackermann (1994) and many others.

The initial adjustement and all subsequent analyses used a Lambert Conformal Conic coordinate system with WGS84 as the horizontal datum and a tide gauge at Rothera research station as the vertical datum.

The tie-points were manually measured to one-pixel precision on clearly defined features such as crevasse intersections and snow patches on rock, well distributed throughout the block. Whilst the GPS ground-surveyed points were accurate to a few $\mathrm{cm}$, they could only be identified with a precision of about $2 \mathrm{~m}$ on the photographs. They were only used to initialise the block-adjustment, required by the LPS software, and to check for gross and systematic errors and were excluded from later iterations of the adjustment and the final block.

The maximum residuals in the block-adjustment exterior orientations for the 53 photographs were $0 \cdot 19,0 \cdot 13$ and $0.19 \mathrm{~m}$ in $\mathrm{X}, \mathrm{Y}$ and $\mathrm{Z}$ directions. The mean 
residuals of the tie-points were respectively $0 \cdot 18,0 \cdot 20$ and $0 \cdot 31 \mathrm{~m}$ with standard deviations of less than $0 \cdot 1 \mathrm{~m}$. Thus the primary block is considered accurate to better than $0.5 \mathrm{~m}$ in $\mathrm{X}, \mathrm{Y}$ and $\mathrm{Z}$ and is regarded as a reliable baseline for extracting secondary control for the historic photographs.

\section{Method for linking the primary block and historic aerial photography}

We used a 3-stage process to achieve a photogrammetric orientation for the different historic aerial photo sets, by tying them to secondary control derived from the primary block.

1. An extra class of tie-points was added to the primary block, chosen on permanent features such as local summits on ridges, rock outcrops and large boulders that could be identified on both the new aerial photographs and each of the historic photography sets in turn. The points did not have to be identical between the historic photo sets. Obviously, features subject to change over the time-period, such as crevasses, could not be used.

2. Re-adjustment of only the primary block, including tie-points common with the historic photos, holding the external orientation parameters fixed, to derive coordinates for the secondary control points with a known precision from the block-adjustment statistics.

3. Separate photogrammetric orientation of the historic photos using the secondary control points, supplemented by new tie-points as necessary.

This procedure was carried out for each of the four historic datasets to achieve five photogrammetric projects spanning 1947 to 2005, which could then be used for measurement of glacier surface change over time. The main difficulty was finding enough points on stable features that could be identified with precision on the different photographs. This was due to a combination of the rugged terrain with little visible rock, the wide variation in seasonal snow cover on the photographs and significant differences in perspective resulting from the different flying directions and photo-scale of the sorties. Nevertheless, it was possible to find enough points for each photography type to give substantial redundancy and a satisfactory adjustment (Table II).

We considered adding all the historic photos into the primary block and performing a simultaneous 'grand adjustment' of all the photography in the study. Whilst this is more elegant and initially attractive, we rejected it due to increased difficulties with detecting errors in the block and data handling, and to ensure that the primary block remained unaffected. 
TABLE II. Summary of block adjustment results for the historic photography sets.

\begin{tabular}{|c|c|c|c|c|}
\hline & \multicolumn{3}{|c|}{$\begin{array}{c}\text { RMSE at the control points (and maximum tie- } \\
\text { point residual), metres }\end{array}$} & \multirow{2}{*}{$\begin{array}{l}\text { Total image unit- } \\
\text { weight } \\
\text { RMSE } \\
\text { (microns) }\end{array}$} \\
\hline & $x$ & $y$ & $z$ & \\
\hline \multicolumn{5}{|l|}{ RARE (4 photos, 1 strip) } \\
\hline 13 SCPs, 46 tie-points & $1.0(1.7)$ & $1.5(1.2)$ & $1.8(2.1)$ & 36.5 \\
\hline \multicolumn{5}{|l|}{ FIDASE (11 photos, 3 strips) } \\
\hline 20 SCPs, 80 tie-points & $1.0(2.4)$ & $0.6(2.1)$ & $1.3(3.4)$ & 31.8 \\
\hline \multicolumn{5}{|l|}{ IfAG (6 photos, 2 strips) } \\
\hline 12 SCPs, 40 tie-points & $1.0(1.9)$ & $0.9(1.3)$ & $1.2(1.5)$ & 11.3 \\
\hline \multicolumn{5}{|l|}{ BAS 1991 (5 photos, 1 strip) } \\
\hline 14 SCPs, 22 tie-points & 0.2 (1.3) & $0.3(1.2)$ & $0.5(1.9)$ & 15.6 \\
\hline & $S C P=S C$ & control & & \\
\hline
\end{tabular}

\section{Approximating missing calibration metadata}

The RARE aerial photography has lost its calibration metadata (Table I) through changes of ownership over the years, but fortunately the focal length is accurately known. Whilst the Fairchild K17 camera used did not expose a data strip inclusing the focal length onto each frame, the calibrated focal length had been written onto the negative of the first frame of each film. However, the fiducial coordinates and the radial lens distortion characteristics are unknown and had to be approximated for this study.

The Fairchild K17 camera used Metrogon lenses, which are known to have maximum radial distortions of over 100 microns, compared with less than 5 microns for a modern aerial photography camera lens. Hothmer (1958) computed the effects of uncorrected radial lens distortion for a typical metrogon lens on height measurement accuracy to be maximum measurement error of up to $1 \%$ of the flying height, ( $3 \mathrm{~m}$ for the RARE photography used here) and more than $0 \cdot 25$ $\%$ for about $3 / 4$ of a stereo-pair. This level of error is unacceptable to achieve the precision required for the glacier change study and requires calculation or approximation of the unknown radial lens distortion parameters to reduce the height measurement error to acceptable levels.

Self-calibrating bundle adjustment (SCBA) is an established technique to calculate unknown calibration parameters or other systematic influences on the photogrammetric adjustment. Chandler and Cooper (1989), for example, demonstrated its potential for back-calculating missing calibration parameters for historic aerial photographs, achieving an average precision of $1 \mathrm{~m}$ RMS for 
photography at comparable scales from 1948-1988 for a project measuring change in a landslip in Dorset.

In SCBA, the photogrammetric collinearity equations are modified to include extra parameters for unknowns that are common to the block, which are then solved as by the block-adjustment process. However this requires redundancy in the computations, which can achieved through increasing the amount of ground control and flying the aerial photography as a block with large overlaps.

In practice SCBA is very difficult to apply successfully to historic aerial photography of mountainous, remote polar areas such as the RARE photographs in this study. Adequate numbers of ground control points are very difficult to acquire and identify on the historic photos with the precision required for successful SCBA. Finally, the RARE photography was acquired as the vertical component of a horizon-to-horizon tri-camera system, and has no overlap between adjacent vertical strips, this further increases the requirement for ground-control for a reliable SCBA .

Thus, for this project we rejected a SCBA approach and instead approximated the distortion curve for the RARE photography by applying a generic curve derived from the characteristics of many other lenses of the same type (Sewell, 1954). Sewell studied 276 Metrogon lenses to establish whether the lenses were sufficiently similar to justify mechanical correction for radial distortion for the analogue stereo-plotters of the day with a universal compensation device. This is a very similar problem to seeking to apply a universal curve to a camera with known lens type but unknown detailed calibration parameters. He found that for $48 \%$ of the lenses the calibrated curve varied less than 10 microns from the average curve of the 276 samples, and for $74 \%$ less than 15 microns, with an overall maximum difference of about 50 microns. Applying the Sewell generic curve was expected to reduce the maximum residual radial distortion to 20 microns and the maximum height error from this source to about $0.2 \%$ flying height, or $0.6 \mathrm{~m}$ for the RARE photography.

\section{Effects on accuracy of using paper prints for RARE and BAS 1991}

Paper warping in decades-old photographic paper prints can introduce significant bias and hence error to photogrammetric surface height measurements. The affine transformation normally carried out during the photogrammetric inner orientation stage minimises the overall effects of paper distortion at the fiducial marks, but paper warping within the photograph frame remains unknown. In order to assess the likely size of this uncorrected warping and its possible impact on height measurement accuracy for this study we analysed a sample of six photographs from a set of photographs from 1969 that were acquired using a Fairchild F49 metric camera fitted with a calibrated reseau grid. The photographs had been stored under the same conditions as the 1947 RARE photographs for at least the last 17 years and we assumed that the response of the photographic paper was similar and that the observed distortions were due to paper warping and not camera problems such as lack of film flatness. Comparison of the calibrated coordinates for each of the 144 crosses in the reseau with measurements made after inner orientation showed complex patterns of warping, unaccounted for by 
the inner orientation, reaching over 100 microns in places. There is complex inter-play between the distortions in the stereo-overlap on adjacent photographs, but their effects on parallax could introduce typical errors of about 1.5 metres at $3,000 \mathrm{~m}$ flying height, with local anomalies of up to 5 metres. Furthermore, the magnitude, direction and distribution of the residual distortions are not sufficiently consistent from photograph to photograph to be modelled and applied as a correction. Most aerial photography does not have the reseau grid and there is thus no way to directly measure the likely effects of residual paper distortions in the practical case, so it is imperative that the original negatives are used for accurate work from historic photographs wherever possible.

For the glacier change project we concluded that height measurement errors from paper distortion of 1.5 to $2.0 \mathrm{~m}$ were plausible for the RARE photography set and included these effects in the overall error budget.

The BAS 1991 aerial photography was also only available as paper prints. However comparing the calibrated and measured fiducial coordinates suggested that paper-warping effects were much less severe. This is attributed to the use of modern, more stable, resin-coated photographic paper for these prints.

\section{RESULTS AND DISCUSSION}

\section{Block adjustment results for the historic photographs}

The block adjustment results for the BAS 2005 primary block were described above. The adjustment results for the four types of historic aerial photography are summarised in Table II.

The X and Y (longitude/latitude) accuracy of all the datasets was better than 2 metres. These errors are insignificant for elevation measurement accuracy on the gently sloping glacier surface, where even the steeper upper parts of the glacier have a gradient of less than $10 \%$, and will not be discussed further.

With incomplete metadata and the use of paper prints, the RARE photographs are the worst-case data for this study, and it was expected that the bundle-adjustment results would be much poorer than for the other datasets. The elevation control point RMSE from 13 control points derived from the primary block was $1.8 \mathrm{~m}$, with the largest residual $4.0 \mathrm{~m}$ and the maximum tie-point $\mathrm{Z}$ residual was $2 \cdot 1 \mathrm{~m}$. The total image unit-weight RMSE, which measures the overall precision of the control and tie-point measurements on the photographs, was 36.5 microns; this is an acceptable value and is still less than 2 pixels. Overall the results show that the measurements were noisier than for the other datasets, but were better than expected. The lower precision reflects the approximated radial distortion data and paper warping and lower image sharpness from using scanned paper-prints.

The FIDASE photography set included a total of 20 control points, which were measured 67 times on the photographs. The elevation RMSE value for the control points was $1.3 \mathrm{~m}$. The total image unit weight RMSE was 31.8 microns, 
about $0.9 \mathrm{~m}$ on the ground, showing that overall the tie-points were measured with high precision. However, there were a few outliers in the individual measurements so that the maximum control and tie-point $\mathrm{z}$ residuals were $2.8 \mathrm{~m}$ and $3.4 \mathrm{~m}$, indicating that the photo-coordinate measurements are noisier. This is attributed to the slight loss of sharpness and scratched condition of the negatives.

The IfAG photography had 12 control points, measured in 23 instances on the photographs. The elevation RMSE of the control point measurements was $1 \cdot 2$ $\mathrm{m}$. The total image unit weight RMSE was $11 \cdot 3$ microns and the maximum residuals were all less than 2 metres. These are excellent results from this highaltitude, super-wide-angle-lens photography, and reflect the extremely high image quality of this photography set.

The BAS 1991 photography has camera calibration data, but only paper prints were available for this study. A total of 14 control points were derived from the primary block and they were measured 34 times on the photographs. The control point elevation RMSE was $0 \cdot 5 \mathrm{~m}$. The total unit weight RMSE was $15 \cdot 6$ microns, which is higher than the values achieved from the similar Zeiss RMK cameras used for the BAS 2005 and IfAG 1989 photography sets; this will be due to warping of the paper prints scanned for this study rather than dimensionallystable negatives. Nevertheless, the maximum residuals were all less than 2 metres. These are very good results from paper prints and indicate a high-quality adjustment for the photographs.

Taken together the block-adjustment results show that the method of transferring ground control from well-constrained aerial photography with direct GPS measurement of the camera centres can achieve photogrammetric orientations for difficult-to-use historic photographs of better than 2 metres RMSE in latitude, longitude and elevation.

The main constraints are: firstly, the availability of points that can be precisely identified on the photographs, especially with different levels of snow cover and different perspective, and secondly, the image quality, where working with paper prints or deteriorating negatives leads to poorer results.

\section{Measurement precision for the historic photography}

The orientation accuracy of the photogrammetric model is only one factor affecting the overall measurement accuracy of the glacier surface heights. This will be a combination of the orientation accuracy and the precision of the photogrammetric measurements from the images. We tested the achievable measurement precision for each of the photography types by collecting 20 independent measurements for a randomly chosen object point on the glacier surface (using Leica Stereo-Analyst software) and calculating the standard deviation and maximum residual for each phot set.

The results are given in Table III and show that the key factors are photoscale/ground resolution and image quality. The image quality of the IfAG photography is very high, but the resolution is lower and so the standard deviation and greatest residual values are higher than the BAS 2005 photographs taken with 
the same camera type and similarly scanned from the negatives. For the other photo sets with photo-scales between 1:20,000 and 1:30,000 image quality is the key factor; the lowest image quality FIDASE photographs have the poorest measurement consistency. Using scanned paper prints does not appear to affect measurement precision greatly; the results for the BAS 1991 and RARE photosets, which were both paper prints are good. As was expected, the BAS 2005 photographs, which were scanned from negatives with a high image quality allowed the best measurement consistency. Nevertheless, a measurement precision with a standard deviation of better than $0.6 \mathrm{~m}$ and with a greatest residual of less than 1 metre was achieved for all the photo sets.

The overall accuracy of the surface elevations is also likely to be lower in areas with poor surface texture, where it is difficult to make high quality photogrammetric measurements. This problem has long been recognised as a constraint for photogrammetry on glaciers. Minimising the effects of low surface texture on measurement accuracy depends on operator skill and discipline not to include measurements with low confidence.

TABLE III. Measurement consistency for the different photography sets from a sample of 20 independent measurements at the same point.

\begin{tabular}{ccccc} 
Photography & Photo scale & Ground resolution $(\mathrm{m})$ & $\begin{array}{c}\text { Standard deviation } \\
(\mathrm{m})\end{array}$ & $\begin{array}{c}\text { Greatest residual } \\
(\mathrm{m})\end{array}$ \\
\hline BAS 2005 & $1: 30,000$ & 0.6 & 0.2 & 0.4 \\
BAS 1991 & $1: 20,000$ & 0.4 & 0.3 & 0.6 \\
IfAG 1989 & $1: 70,000$ & 1.4 & 0.4 & 0.8 \\
FIDASE 1957 & $1: 27,000$ & 0.5 & 0.5 & 0.9 \\
RARE 1947 & $1: 20,000$ & 0.4 & 0.3 & 0.5
\end{tabular}

\section{Overall accuracy against independent check data}

It is difficult to quantify the absolute accuracy of the photogrammetric orientations because there is no independent check data such as contemporary ground survey for any of the historic datasets.

One method could be to check the consistency of a sample of points on stable, rock features around the glacier from the historic datasets against the BAS 2005 photo-block, which is regarded as error-free for this project. However, in practice this is difficult to apply because suitable places on ridges, summits and nunataks are scarce and have usually been used as secondary control point locations. The bundle-adjustment process minimizes error at the control points, so check points located close to the GCPs are not a valid test of accuracy. Suitable points could only be found for the FIDASE photographs, but this is the dataset with the highest maximum control point and tie-point block adjustment residuals and thus potentially the most variable error throughout the block. The mean of the errors at 5 sample points was $-1.0 \mathrm{~m}$, showing a negative bias, with a standard deviation of $0.8 \mathrm{~m}$, these values are in line with the orientation results. 
Superimposition of contours for the rocky areas compiled from the 2005 data in stereo-models with the historic photographs gives a useful subjective assessment of their photogrammetric orientation quality.

All the photo sets had substantial coverage of the coastline, and so we used the high-water mark and fast-ice (sea-ice which is fastened to the shoreline and not moving) as an independent check of elevation accuracy. The high-water mark is believed to be about $1 \mathrm{~m}$ at this location and about $0.25 \mathrm{~m}$ is a plausible freeboard for old fast ice. The results from the check measurements are summarized in Table IV. They exceeded our expectations from the photogrammetric orientation results and are taken to confirm the effectiveness of the technique.

A further imponderable is the effect of seasonal and inter-annual variations in the snow cover on the glacier. Most of the photographs used in this study were acquired in January, but the RARE photographs were taken in November. The different photo sets show a great variation in snow cover on the beaches, moraines and nunataks, which indicate that there is likely to be a significant variation in the glacier snow cover also, at least in the lower parts of the glaciers. Annual snowfall is probably about $2 \mathrm{~m}$ for this part of the Antarctic Peninsula, (van Lipzig et al., 2004). Thus, variations in the snow cover according to the time of year of the photographs could be as significant as the precision of the photogrammetric measurements.

TABLE IV. Elevation measurement accuracy against high water mark and fast-ice freeboard used as check data

\begin{tabular}{cccc} 
Photo type & Mean measurement $(m)$ & Standard deviation $(m)$ & Number of samples \\
\hline RARE 1947 & 1.1 & 0.2 & 20 \\
FIDASE 1957 & 1.4 & 0.2 & 8 \\
IfAG 1989 & 1.3 & 0.3 & 13 \\
BAS 1991 & 1.1 & 0.2 & 20
\end{tabular}

\section{COMPARISON OF GLACIER SURFACE DEMS}

The purpose of this study was to test whether an acceptable photogrammetric orientation could be achieved with the photography types and other constraints for the Antarctic Peninsula. Hence Moider glacier was chosen as a test site primarily for the range of historic aerial photograph types and ease of access from Rothera Research Station, rather than for having ideal surface characteristics for photogrammetry.

Nevertheless, we here present a comparison of glacier surface DEMs at the five epochs. For each epoch, data points were digitized on the glacier surface using Leica Stereo-Analyst software and then DEMs generated using the Inverse Distance Weighted strategy in ESRI's ArcScene software.

Because surface texture was not a key factor in choice of study glacier poor ground texture prevented photogrammetric height measurement for some areas at some epochs. Two study areas were defined by intersecting areas with an 
acceptable data point density of the 1957, 1989 and 2005 epoch, and all five epochs respectively (labelled 1 and 2 in Fig. 4). Differential DEMs were calculated for the study areas and as a result the total ice volume change over the different epochs was calculated, defining the most recent dataset (2005) as a null dataset. Results with error bars (which have been calculated from the surface height RMSE of each epoch) are shown in Fig. 5. The size of the error bars compared to the absolute volume change show that the signal to noise ratio with this method is acceptable for identifying trends in deglaciation.

\section{CONCLUSIONS}

This study shows that the method of transferring control from highly accurate GPS-supported photogrammetry to difficult-to-use historic photographs is effective under the constraints below.

The results show that the primary GPS-supported aerial photography can be orientated with an accuracy of better than $0.5 \mathrm{~m}$. Secondary ground control points can be transferred to other historic photosets to allow their photogrammetric orientation to be better than $2 \mathrm{~m}$ RMSE in X, Y and Z, even for photographs using paper prints and approximated calibration metadata. Measurements of elevation for surfaces with good texture can be made with a consistency of better than $0.6 \mathrm{~m}$ standard deviation and a greatest residual of better than $1 \mathrm{~m}$. Overall measurement accuracy of better than $2 \mathrm{~m}$ for all the photo sets was supported by comparison with limited independent check data.

The main limitations on measurement accuracy are the image quality for the historic photographs and using paper prints. The well-known inability to measure areas with featureless snow surfaces remains an intrinsic limitation for photogrammetry on glaciers. Variations in snow-cover due to time of year and inter-annual differences may be as important for the overall results as the photogrammetric measurement accuracy.

This method is a significant step forward for measuring glacier volume change on the Antarctic Peninsula, where difficulties with acquiring adequate ground-surveyed photo-control and the characteristics of the historic photography have always hampered photogrammetry. The research also demonstrates the importance of maintaining and updating the photographic archive.

We are now seeking to apply the method in a larger-scale study to measure volume change for benchmark glaciers on the Antarctic Peninsula.

\section{NEXT STEPS}

We are now seeking to apply the method in a larger-scale study to measure volume change for 14 benchmark glaciers on the Antarctic Peninsula.

Any attempt to apply the method to a larger number of glaciers and photographs would require further automation of the method to increase efficiency. In the method described here, the most time-consuming stages are collecting tie-points for orientation of the new reference photography and measuring the surface height samples. 
One clear opportunity for improving efficiency is direct measurement of full exterior orientation parameters for the new reference photography with an INS/GPS system, thus eliminating the need for laborious tie-point measurement. Alternatively automated tie-point measurement could also speed exterior orientation of the reference photography sets.

Automated generation of DEMs for the glacier surfaces with the image matching methods now fully implemented in photogrammetric software would be critical for any large-scale programme of photogrammetric glacier surface measurement. However, sparse surface texture for some Antarctic Peninsula glaciers is likely to limit efficiency gains from this method.

\section{REFERENCES}

ACKeRmanN, F., 1994. Practical experience with GPS supported aerial triangulation. Photogrammetric Record, 14(84): 861-874.

Andreassen, L. M., Elvehøy, H. and KJøllmoen, B., 2002. Using aerial photography to study glacier changes in Norway. Annals of Glaciology, 34: 343-348.

Chandler, J. H. and CoOPER, M. A. R., 1989. The extraction of positional data from historical photographs and their application to geomorphology. Photogrammetric Record, 13(73): 69-78.

CoOK, A., Fox, A. J., VAughan, D. G. and FerRignO, J. G., 2005. Retreating glacier fronts on the Antarctic Peninsula over the past half century. Science, 308: 541-544.

ETZELMÜLLER, B. and SOLLID, J. L., 1997. Glacier geomorphometry - an approach for analysing longterm glacier surface changes using grid-based digital elevation models. Annals of Glaciology, 24: 135-141.

FAVey, E., PAteraki, M., Baltsavias, E.P., Bauder, A., and BÖsch, H., 2000. Surface modelling for alpine glacier monitoring by airborne laser scanning and digital photogrammetry. International Archives of Photogrammetry and Remote Sensing, 33(4): 269-277.

FINSTERWALDER, R., 1954. Photogrammetry and glacier research with special reference to glacier retreat in the eastern Alps. Journal of Glaciology, 2(15): 306-315.

GRÜN, A., COCARD, M., AND KAHLE, H. G., 1993. Photogrammetry and kinematic GPS: results of a high accuracy test. Photogrammetric Engineering and Remote Sensing, 59(11): 1643-1650.

Hothmer, J., 1958. Possibilities and limitations for elimination of distortion in aerial photographs (Part 1). Photogrammetric Record, 2(12): 426-445.

KING, J. C., 2003. Antarctic Peninsula climate variability and its causes as revealed by analysis of instrumental records. Antarctic Peninsula Climate Variability: Historical and Paleoenvironmental Perspectives. Antarctic Research Series, 79, American Geophysical Union, Washington, DC. 260 pages:17-30.

VAN LipZig, N. P. M., King, J. C., LAChlan-Cope, T. A. and VAN DEN Broeke, M. R., 2004. Precipitation, sublimation and snow drift in the Antarctic Peninsula region from a regional atmospheric model. Journal of Geophysical Research, 109, D24106, doi: 10·1029/2004JD004701.

VON BARSCH, D. and HELL, G., 1975. Photogrammetrische Bewegungsmessungen am Blockgletscher Murtèl I, Oberengadin, Schweizer Alpen. Zeitschrift für Gletscherkunde und Glazialgeologie, 11(2): 111-142.

LUCAS, J. R., 1987. Aerotriangualtion without ground control. Photogrammetric Engineering and Remote Sensing, 53(3): 311-314.

Morris, E. M., and Mulvaney, R., 2004. Recent variations in surface mass balance of the Antarctic Peninsula ice sheet. Journal of Glaciology, 50(169): 257-267.

Morris, E. M., and VAughan, D. G., 2003. Spatial and temporal variation of surface temperature on the Antarctic Peninsula and the limit of viability of ice shelves. Antarctic Peninsula Climate Variability: Historical and Paleoenvironmental Perspectives. Antarctic Research Series, 79, American Geophysical Union, Washington, DC. 260 pages: 61-68.

PRitchard, H., and VAughan, D. G., 2007. Widespread acceleration of tidewater glaciers on the Antarctic Peninsula. Journal of Geophysical Research, 112, F03S29, doi:10•1029/2006JF000597. 
Rentsch, H., Welsch, W., HeipKe, C. and Miller, M. M., 1990. Digital terrain models as a tool for glacier studies. Journal of Glaciology, 36(124): 273-278.

Rignot, E., Casassa, G., Gogineni, P., Krabill, W., Rivera, A. and Thomas, R., 2004. Accelerated ice discharge from the Antarctic Peninsula following the collapse of Larsen B ice shelf. Geophysical Research Letters, 31, L18401, doi:10·1029/2004GL020679.

Rignot, E., Casassa, G., Gogineni, S., Kanagaratnam, P., Krabill, W., Pritchard, H., RiverA, A., Thomas, R., Turner, J. and Vaughan, D., 2005. Recent ice loss from the Fleming and other glaciers, Wordie Bay, West Antarctic Peninsula. Geophysical Research Letters, 32, L07502, doi:10·1029/2004GL021947.

RotT, H., Skvarca, P. and Nagler, T., 1996. Rapid collapse of Northern Larsen Ice Shelf, Antarctica. Science, 271: 788-792.

Scambos, T.A., HulBe, C., Fahnestock M. and Bohlander, J., 2000. The link between climate warming and break-up of ice shelves in the Antarctic Peninsula. Journal of Glaciology, 46(154): 516-530.

ScAmbos, T. A., Bohlander, J.A., Shuman, C.A., and SkVARCA, P., 2004. Glacier acceleration and thinning after ice shelf collapse in the Larsen B embayment, Antarctica. Geophysical Research Letters, 31, L18402, doi 10·1029/2004GL020670.

SEWELL, E.D., 1954. Distortion - Planigon versus Metrogon. Photogrammetric Engineering, 20(1): 54-58.

Smith, A. M., Vaughan, D. G, Doake, C. S. M. and Johnson, A. C., 1998. Surface lowering of the ice ramp at Rothera Point, Antarctic Peninsula, in response to regional climate change. Annals of Glaciology, 27: 113-118.

Vaughan, D. G., Marshall, G. J., Connelly, W. M., Parkinson, C., Mulvaney, R., Hodgson, D. A., King, J. C., PuDSEY, C. J. and TURnER, J., 2003. Recent rapid regional climate warming on the Antarctic Peninsula. Climatic Change, 60(3): 243-274.

Vaughan, D. G., 2006. Recent trends in melting conditions on the Antarctic Peninsula and their implications for ice-sheet mass balance and sea level. Arctic, Antarctic, and Alpine Research, 38(1): 147-152.

\section{Résumé}

\section{Zusammenfassung}

Jüngste Studien im Bereich der Antarktischen Halbinsel dokumentieren den Zusammenhang zwischen regionaler Erwärmung und ausgedehntem Gletscherrückgang. Obwohl die Eisschmelze ein wesentlicher Faktor für den vorhergesagten Meeresspiegelanstieg darstellt, ist der genaue quantitative Zusammenhang unbekannt. Grund dafür war bislang das Fehlen an Rohdaten.

Um in Zukunft bessere Aussagen über die Auswirkungen der Gletscherschmelze auf den Meeresspiegel treffen zu können, ist es notwendig, genaue Messungen der Gletscheroberflaechen und Berechnungen der Volumsänderungen durchzuführen.

In den Archiven einschlägiger Organisationen existieren über 30,000 historische Luftbilder, die bis in die 1940er Jahre zurückgehen. Diese Bilder sind die einzigen Belege, die die Veränderungen der Eismassen während der letzten sechzig Jahre dokumentieren. Die Schwierigkeit diese Dokumente sinnvoll nutzen zu können liegen 
allerdings im Detail: das Fehlen von Passpunkten, unvollständige Kalibrierungsdaten, schlecht gewählte Flugrouten und das teilweise Fehlen der Original-Negative machen genaue Messungen schwierig.

In diesem Beitrag wird eine Methode vorgestellt, wie diese historischen Fotografien dennoch und ohne aufwendiger Feldarbeit ausgewertet werden können. Betrachtungen über die erzielbaren Genauigkeiten und ein Beispielprojekt runden den Bericht ab.

Mit der vorgestellten Methode wurden Messgenauigkeiten besser als $2 \mathrm{~m}$ RMSE erzielt. Diese Werte erlauben Messungen der Eisoberfläche die genau genug sind, um verlässliche Aussagen über die Abnahme der Eismassen über den Zeitraum von Jahrzehnten zu treffen. Die wichtigsten Faktoren in Bezug auf die erzielbaren Genauigkeiten stellen die Bildqualität der historischen Fotos und das Fehlen von Original-Negativen dar.

\section{FIGURES AND CAPTIONS}

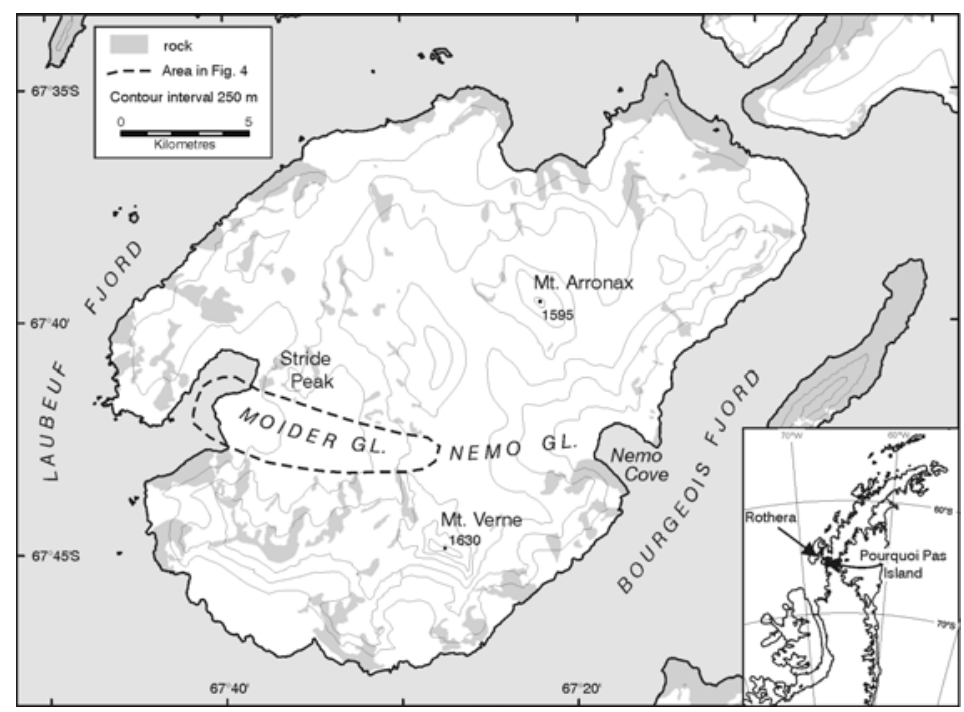

FIG. 1. Location map for Moider Glacier and Pourquoi Pas Island 
FOX and CZIFERSZKY. Unlocking the time-capsule of historic aerial photography

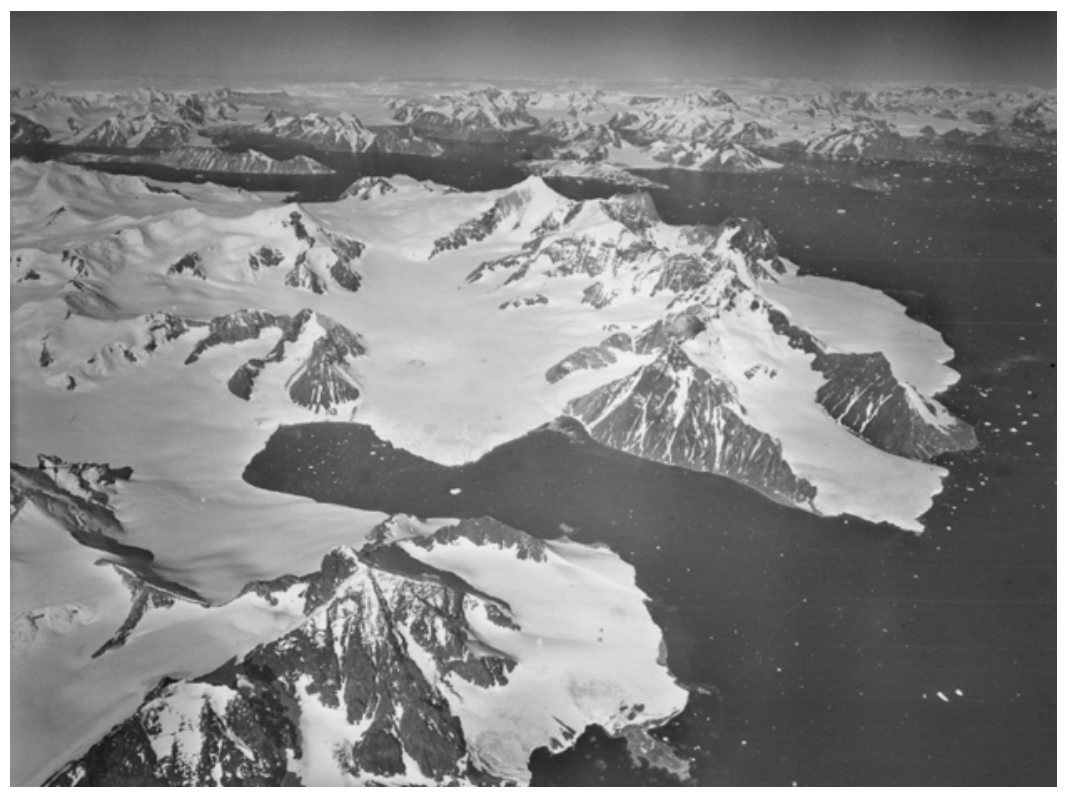

FIG. 2. Photograph of Moider Glacier (centre) and Pourquoi Pas Island terrain (1957), looking east.

BAS $20054,500 \mathrm{~m}$

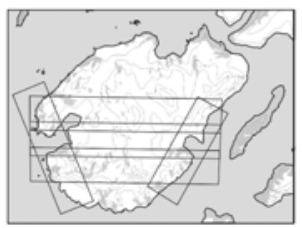

BAS $19913,000 \mathrm{~m}$

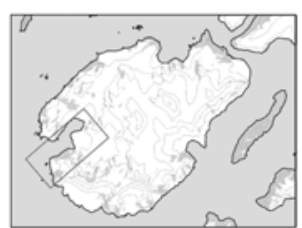

IfAG 1989 6,000 m

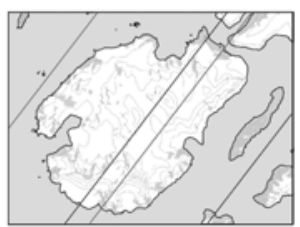

FIDASE 1957 4,000 m RARE 1947 3,000 m
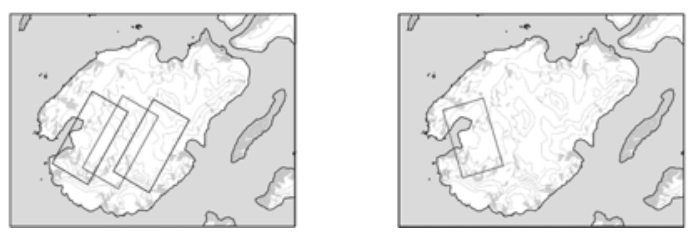

FIG. 3. Aerial photographic coverage and flying altitude for Moider glacier. 


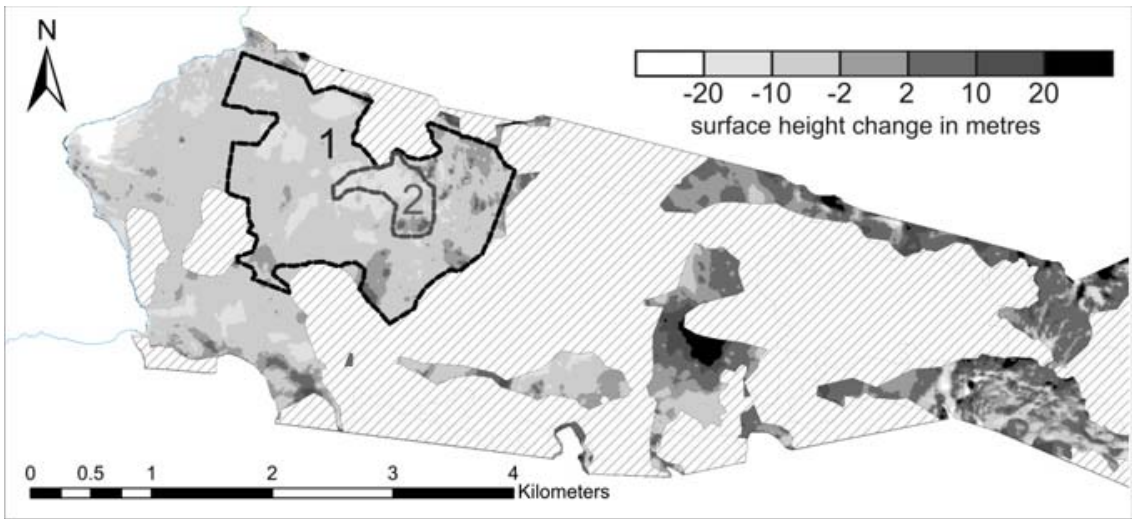

FIG. 4. Glacier surface change for Moider glacier, 1957-2005. Hatched areas show sections of the glacier where lack of texture prevented surface measurement.
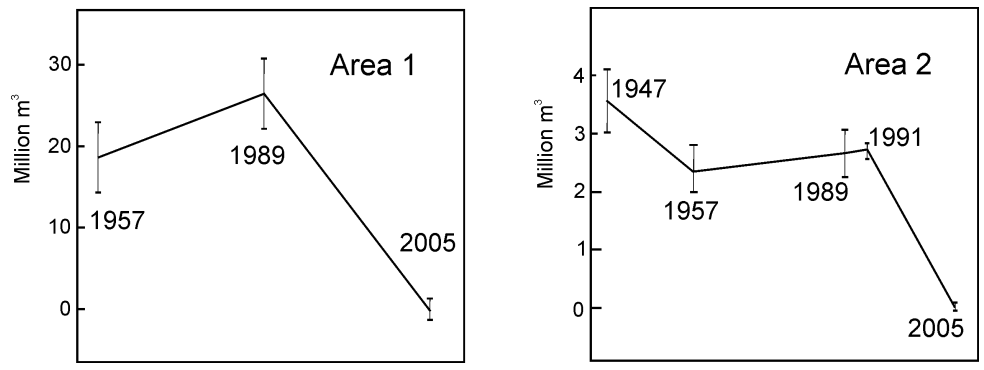

FIG. 5. Volume change for parts of Moider Glacier shown in Fig. 4. The error bars are uncertainty in the volume change from the expected measurement error for each comparison pair. 